\title{
Psicologia no Ensino Médio e Psicologia Escolar: história, diferenças e perspectivas
}

\author{
Lucas Antunes Machado \\ Pontifícia Universidade Católica do Rio Grande do Sul - Porto Alegre - RS - Brasil
}

\begin{abstract}
Resumo
Este artigo objetiva apresentar uma reflexão relativa ao ensino de Psicologia nas escolas e suas diferenças em relação à Psicologia Escolar. Trata-se de uma revisão da literatura especializada através da consulta de periódicos e teses/dissertações. Procedeu-se a busca bibliográfica nas bases de dados eletrônicas SciELO, PePSIC, Indexpsi, CAPES e BDTD. Assim, constatou-se que: (I) o ensino de Psicologia tem marcado presença na formação das juventudes desde metade do século XIX; (II) a Psicologia no Ensino Médio se refere ao espaço de formação e socialização do conhecimento acumulado pela psicologia; (III) a Psicologia Escolar constitui-se como área de aplicação da Psicologia na escola e (IV) têm se intensificado os debates nos âmbitos institucional e político. Conclui-se que o ensino de Psicologia objetiva a formação social crítica dos jovens, reverberando-se nas barreiras psicológicas que legitimam a barbárie e desqualificam valores e atitudes voltados aos direitos humanos e à cidadania na escola
\end{abstract}

Palavras-chave: Ensino da psicologia; psicologia escolar; ensino médio.

\section{Psychology in Secondary Education and School Psychology: history, differences and perspectives}

\begin{abstract}
This article aims to present a reflection about the psychology of teaching in schools and their differences from the School Psychology. This is a review of the literature through regular consultation and thesis / dissertations. Proceeded to the literature search in electronic databases SciELO, PePSIC, IndexPsi, CAPES and BDTD. Thus, it was found that: (i) the teaching of Psychology has been present in the training of youths from midnineteenth century; (II) Psychology in high school refers to the area of training and socialization of knowledge accumulated by psychology; (III) School Psychology was established as the psychology area of application in school and (IV) they have intensified discussions in the institutional and political levels. It follows that the objective of Psychology teaching critical social training of young people is reverberating on the psychological barriers that legitimize barbarism and disqualify values and attitudes focused on human rights and citizenship in school.
\end{abstract}

Keywords: Psychology education; school psychology; secondary education.

\section{Psicología en la Enseñanza Secundaria y Psicología Escolar: historia, diferencias y perspectivas}

\section{Resumen}

Este artículo tiene por objetivo presentar una reflexión relativa a la enseñanza de Psicología en las escuelas y sus diferencias en relación a la Psicología Escolar. Se trata de una revisión da literatura especializada por intermedio de la consulta de periódicos y tesis/disertaciones. Se procedió la búsqueda bibliográfica en las bases de datos electrônicas SciELO, PePSIC, Indexpsi, CAPES y BDTD. Así, se constató que: (I) la enseñanza de Psicología ha marcado presencia en la formación de las juventudes desde la mitad del siglo XIX; (II) la Psicología en la Enseñanza Secundaria se refiere al espacio de formación y socialización del conocimiento acumulado por la psicología; (III) la Psicología Escolar se constituyó como área de aplicación de la Psicología en la escuela y (IV) se tiene intensificado los debates en los ámbitos institucional y político. Se concluye que la enseñanza de Psicología objetiva la formación social crítica de los jóvenes, reverberando-se en las barreras psicológicas que legitiman la barbarie y descalifican valores y actitudes volcados a los derechos humanos y a la ciudadanía en la escuela

Palabras clave: Enseñanza de psicología; psicología escolar; educación secundaria. 


\section{Introdução}

O ensino de Psicologia no Ensino Médio vem sendo reconhecido na literatura nacional (Amado, 2013; Barros, 2007; Cirino, Knupp, Lemos, \& Domingues, 2007; Cirino \& Miranda, 2013; Dadico, 2009; Kohatsu, 2010; Klinko \& Sekkel, 2010; Leite, 2007; Mrech, 2007, 2013; Massimi, 1993; Maciel, 2009; Machado \& Sekkel, 2013; Pacheco, Silva, Gogo, Agnes, \& Jesus, 2011; Pandita-Pereira \& Sekkel, 2012; Simões \& Paiva, 2007; Sekkel \& Machado, 2007; Souza, 2007; Soligo \& Azzi, 2008, 2009; Silva, 2005, 2011). Esse interesse se dá no bojo da histórica presença da Psicologia no Ensino Médio e da atual Resolução n 5/2011, que institui as Diretrizes Curriculares Nacionais (DCN) e estabelece normas para o projeto pedagógico complementar para a formação de professores.

Tendo em vista a história do ensino de Psicologia no Ensino Médio, as legislações que embasam a formação em Psicologia e educação e a instituição das DCN de 2011, este artigo objetiva desenvolver uma discussão sobre Psicologia no Ensino Médio, no que se refere ao ensino dessa disciplina na educação básica. Pretende-se, com isso, suscitar um maior interesse, por parte de alunos, professores e pesquisadores em Psicologia, no campo da formação de professores de Psicologia para educação básica. Também almeja-se dar visibilidade às reais contribuições que a Psicologia tem para a educação e vice-versa e verificar como essas duas ciências se retroalimentam em seu processo histórico na formação de pessoas.

Entendendo a importância da escola na formação dos alunos, uma vez que sua função é complementar à educação familiar, e partindo-se da ideia da escola como uma espécie de "estágio" entre a família e a sociedade, não se pode conceber a educação escolar só como transmissora de conteúdos, mas também como local de formação de cidadãos (Tiba, 2007). Portanto, a escola emerge como uma das instituições fundamentais para o desencadeamento dos processos evolutivos das pessoas (Dessen \& Polonia, 2007). De acordo com Maciel (2009), a atuação do psicólogo atualmente se expande por diversas áreas, sendo elas: clínica, organizacional, educacional, jurídica, entre outras. E, dentre essas áreas, se destaca a possibilidade de atuação profissional como professor de Psicologia no Ensino Médio para o licenciado em Psicologia, tendo este respaldo legal se licenciado para ser responsável pelo ensino neste nível.

Nessa perspectiva, a ciência psicológica pode oferecer conceitos científicos apropriados que subsidiem discussões, debates e reflexões em torno do mundo subjetivo dos jovens, não descartando as dimensões éticas e políticas. Assim, é fundamental que o aluno desenvolva habilidades e competências para convivência (Perrenoud, 2013) ainda que, na escola, se priorize uma formação técnica (Silva, 2005, 2011), pois o investimento educacional tem que ser voltado para o aspecto humano.

\section{Histórico das discussões sobre a Psicologia no Ensino Médio}

A ciência psicológica surge oficialmente no ano de 1879, marcada, sobretudo, por um histórico de discussões e sustentada em diferenciados fundamentos (Penteado \& Guzzo, 2010). Investiga o seu objeto de estudo - o homem - à luz de diversos recortes representados por diferentes áreas do conhecimento, a saber: Psicologia da Educação, Psicologia do Desenvolvimento, Psicologia das Diferenças e Psicometria (Almeida \& cols., 2007).

A relação entre a Psicologia e a educação teve sua trajetória marcada por diversas polêmicas. Uma delas se refere ao fato de a escola sempre esperar que o profissional da Psicologia resolva os problemas da criança que não aprende ou que apresenta comportamentos agressivos (Penteado \& Guzo, 2010), ideia essa coadunada com a perspectiva instaurada a partir do século XIX, que torna a escola alvo de propostas higienistas e de caráter moral que propunham regras de conduta que deveriam ser aplicadas aos alunos para prevenção de comportamentos nocivos ou fora da normalidade (Gomes, 2012). Havia, portanto, a crença de que o trabalho psicológico nas escolas estava associado, sobremaneira, à resolução de problemas, às dificuldades das crianças portadoras de queixa escolar e às funções de diagnosticar crianças problemáticas e perturbadoras quando comparadas às crianças ideais (Molon, 2002).

O ensino de Psicologia tem marcado presença na formação do sujeito sócio-histórico. Tal fato se dá, acima de tudo, em virtude da presença da Psicologia no campo da educação que se confunde com a sua própria história de inserção no Brasil. É na metade do século XIX que a Psicologia ingressa no cenário educacional como disciplina no ensino regular (Soligo \& Azzi, 2008). Ainda segundo Vechia e Lorenz (1998) e Soligo \& Azzi (2008), a Psicologia entra no ensino regular em uma cadeira de Filosofia do colégio Pedro II em 1850. Mrech (2007) faz alusão à Reforma Benjamin Constant, quando a disciplina de Filosofia foi substituída pela disciplina de Psicologia e Lógica, que, posteriormente, originou a disciplina Pedagogia e Psicologia. Por volta de 1890, a Psicologia passa a compor o currículo das escolas normais na disciplina Pedagogia e Psicologia (Mrech, 2007, 2013; Soligo \& Azzi, 2008). No que concerne à formação de professores no Ensino Médio (Magistério) e no ensino superior (Pedagogia e licenciaturas por áreas), a Psicologia sempre esteve presente enquanto disciplina, ocupando posição de destaque até hoje (Soligo \& Azzi, 2009).

As escolas normais surgem a partir da terceira década do século XIX, em um cenário sociocultural brasileiro que apresenta um quadro de má formação de professores e baixa remuneração (Mrech, 2013). Tais escolas trazem importantes contribuições para os primórdios da relação Psicologia e Educação e se constituem em importante sustentáculo do ensino de Psicologia (Gomes, 2012). Todavia, com os deslocamentos das políticas públicas para a educação, sobretudo no investimento da formação qualificada de professores formadores, em 1930 surgem algumas universida- 
des estratégicas para processo de formação de professores no país (Mrech, 2013).

O ensino secundário no Brasil do século XIX estava entregue à iniciativa privada num contexto em que à disciplina Psicologia se conferia um status de formadora em diversas escolas brasileiras, levando à elaboração de projetos de lei que previam a sua inserção nos currículos secundários e superiores (Massimi, 1993). Um dos motivos sobre os deslocamentos da disciplina Psicologia na formação de adolescentes e jovens nessa etapa da educação são as sucessivas modificações nos rumos das legislações da educação brasileira, como, por exemplo, a Lei de Diretrizes e Bases da Educação Nacional (LDB), de 1996 (Soligo \& Azzi, 2009).

Um exemplo de como a legislação da educação brasileira se reverbera nas questões relativas ao ensino de Psicologia está na LDB, Lei nº 5.692 (1971), engendrada nos anos de 1970, ápice do período da ditadura militar no Brasil. Nesse período, as disciplinas como Psicologia, Filosofia e Sociologia foram suprimidas do currículo do Ensino Médio regular com o objetivo de manter parâmetros capitalistas, controlar demandas de uma população reivindicatória e estar de acordo com os preceitos da Doutrina de Segurança Nacional (Dadico, 2009; Soligo \& Azzi, 2009; Souza, 2007). Para tal, seria necessário que disciplinas das ciências humanas fossem retiradas do currículo, pois estas representavam uma ameaça já que, em seu processo de ensino, estava implicado o desenvolvimento de reflexões, contestações, questionamentos e senso crítico dos jovens.

Porém, mais de 20 anos depois, segundo Barros (2007), já no período de transição para o governo democrático, há um novo rudimento de interesse por parte dos psicólogos pela educação básica do cidadão, configurando-se, assim, uma nova fase dessa relação. Segundo o autor, a Lei $n^{\circ} 7.044$ (1982) coloca o Ensino Médio não mais como fase de qualificação para o trabalho, como exigido pela Lei $n^{\circ}$ 5.692 (1971), mas sim como fase de preparação para este. Não sendo qualificação e preparação construtos iguais, deve-se entender que esse novo posicionamento tende a favorecer um projeto de formação de cidadãos que façam uma leitura mais indagativa e crítica em relação ao mundo em que vivem. É nesse contexto que a Psicologia, como disciplina formadora, reencontra um espaço vivo e dinâmico de inserção e diálogo com a educação dos jovens brasileiros.

Disciplinas como Psicologia, Sociologia e Filosofia desempenham um papel que vai além da simples assimilação de conteúdos para a preparação de uma mão de obra técnica. A função das ciências humanas é a formação, no e para o sujeito, de um senso crítico, emancipador, inovador, criador e humanizado. É nesse sentido que a inclusão de disciplinas como Sociologia, Filosofia e Psicologia tem como objetivo a formação de cidadãos críticos e que se envolvam com as questões relacionadas à sua realidade social e política e que o desenvolvimento dos jovens não se restrinja apenas a uma visão técnica, que visa ao melhor desempenho no mercado de trabalho ou à aprovação nos vestibulares, mas que também ambicione a construção de um sujeito que habite e opere mudanças na sua realidade social (Klinko \& Sekkel, 2010).

Foi no âmago de diversas modificações legislativas da educação em conjunto com o que estudiosos e especialistas da época pensavam e produziam a respeito do ensino de Psicologia no Ensino Médio que os Conselhos Regionais de Psicologia e sindicatos reforçaram e intensificaram as discussões sobre a importância da implementação da Psicologia para a formação dos jovens. O surgimento da $1^{\mathrm{a}}$ Comissão de Ensino do Conselho Regional de Psicologia de São Paulo, em 1982, é um exemplo.

A partir de 1980, o ensino da ciência no Ensino Médio, objeto deste artigo, passa a ser alvo de diversas discussões sindicais da Psicologia. A notícia de que um concurso para professores que abrangia as disciplinas de ciências humanas, incluindo a Psicologia, seria realizado no ano de 1986 foi o principal responsável pela aproximação e pelas parcerias entre a Secretaria de Estado da Educação, o Conselho Regional de Psicologia de São Paulo e a Coordenadoria de Estudos de Normas Pedagógicas - CENP (Leite, 2007; Soligo \& Azzi, 2008). Dessa aproximação originou-se um curso denominado "Psicólogo - Docente no Ensino de $2^{\circ}$ Grau" e um livro chamado "Psicologia no Ensino de $2^{\circ} \mathrm{Grau}$ - Uma proposta Emancipadora”, que até hoje representa a primeira proposta efetiva de conteúdos a serem trabalhados por licenciados em Psicologia no Ensino Médio, além de ser referência na área. Ainda, constata-se que a disciplina de Psicologia passou, nos anos 80, a figurar como obrigatória nas escolas de ensino propedêutico do Estado de São Paulo (Souza, 2007; Soligo \& Azzi, 2008).

A década de 90 marca uma supressão dessa disciplina, que passa a compor o núcleo diversificado dos currículos do Ensino Médio a caráter eletivo (Soligo \& Azzi, 2008). Todavia, as mesmas autoras destacam nova iniciativa da Secretaria da Educação e do Conselho Federal de Psicologia no sentido de redefinir os parâmetros curriculares para o Ensino Médio. Nessa proposta, a Psicologia figuraria como disciplina obrigatória nesta etapa do ensino, o que gerou uma série de estudos e publicações de textos que versavam sobre essa temática, contudo não se efetivou a incorporação da disciplina Psicologia no Ensino Médio propedêutico.

Mrech (2007) destaca que, desde a década de 90, professores de Psicologia do Ensino Médio não têm nenhum tipo de capacitação ou atualização no que tange a sua formação docente, o que acaba desencadeando problemas nas práticas em sala de aula. Um exemplo é o que ocorre com professores de Psicologia que não têm ideia de que conteúdos ensinar quando se deparam com a docência dessa disciplina no Ensino Médio. A falta de um conteúdo programático, confusões entre o psicólogo escolar e o professor de Psicologia, professores que se direcionam para práticas alternativas de orientação vocacional e orientação sexual por não saberem o que ensinar são alguns dos entraves encontrados pelos professores de Psicologia. A autora ainda destaca a predominância de conteúdos de Psicologia de senso comum nas aulas e a falta de clareza do que é o ensino de Psicologia e a licenciatura em Psicologia para 
alguns professores de ensino superior como algumas das dificuldades que podem ser observadas em disciplinas como Metodologia do Ensino de Psicologia, no que se refere à prática do ensino da Psicologia na sala de aula (Mrech, 2007).

Alguns psicólogos entendem a formação docente em Psicologia como sendo uma atividade de menor valor e que a atuação do profissional deveria, por excelência, estar voltada para as áreas da Psicologia Clínica, Psicologia Social ou Psicologia Crítica (Mrech, 2007), em detrimento da atuação desse profissional na educação. Essa condição alinha-se com a história da Educação, que está voltada para o pensamento de que qualquer área ligada a ela, sobretudo a docência, tem menor valor e prestígio social. Pode-se pensar que isso ocorre devido ao fato de que o profissional dessa área trabalha por longas jornadas que se revertem, por sua vez, em uma remuneração pouco ou nada condizente com o tempo e a dedicação dispensados à profissão e pelo pouco prestígio social atribuído à carreira docente.

É importante destacar que, em momentos distintos, diversas foram as iniciativas tomadas na intenção de reavivar os estudos e pesquisas no que tange ao ensino da disciplina Psicologia no Ensino Médio regular (Soligo \& Azzi, 2008), e que, embora se reconheça que a abordagem dessa temática tenha tido realidades diversas nos diferentes Estados, reconhecem-se a importância e relevância que o tema ensino de Psicologia teve no Estado de São Paulo. No período de 1980 a 2000, quando houve massiva retomada do tema, no que Leite $(2007$, p. 11) discorre que "movimento de organização coletiva da categoria ... demonstrou aspectos muito relevantes e historicamente importantes", que se desdobrou em documentos que são, até hoje, referência para os interessados no tema.

Ainda sobre a importância dada ao ensino de Psicologia na cidade de São Paulo, Barros (2007, p. 34) pondera que "em 1984, 454 escolas de $2^{\circ}$ grau do Estado de São Paulo tinham a disciplina de Psicologia em seu currículo; em 1985, 445; em 1986, 603; e em 1987, 593". Essa inconstância no número de escolas que ofereciam a disciplina originou em 1990 uma "Proposta curricular de Psicologia para o ensino de $2^{\circ}$ Grau", elaborada pela Secretaria de Educação de São Paulo, por meio da CENP, que obteve uma reedição no ano 1992.

Tendo-se percorrido pelo histórico de discussões que problematizaram as questões relativas ao ensino de Psicologia no Ensino Médio, é importante que se discorra agora sobre uma diferença que é fundamental quando se fala em Psicologia nas escolas, aquela entre Psicologia Escolar e o ensino de Psicologia. Essa diferenciação se faz necessária, acima de tudo, pela confusão que pode ser feita, principalmente por outros profissionais da escola (professores, pedagogos, orientadores pedagógicos, direção, entre outros), no que tange às atribuições do professor de Psicologia e do psicólogo escolar, que, embora trabalhem em conjunto no ambiente escolar, têm funções diferentes e que devem ser caracterizadas para uma boa efetivação de ambas.

\section{Diferença entre Psicologia Escolar e ensino de Psicologia}

Diferenciar o exercício profissional de psicólogo escolar do professor de Psicologia na escola é fundamental, uma vez que ambos compartilharão de um mesmo universo ou campo de atuação - a escola -, ainda que assumindo diferentes funções. Portanto, se faz necessário o entendimento por parte tanto de profissionais psicólogos quanto dos demais profissionais do campo da educação sobre os papéis e limites de atuação entre um e outro.

No contexto escolar, ocorrem divergências e, não raras vezes, conflitos entre o entendimento acerca das atribuições do papel do psicólogo escolar e demais profissionais, principalmente no que se refere ao papel do professor de Psicologia do Ensino Médio. Verifica-se a ambiguidade de papéis nesses profissionais, por meio da solicitação, por parte da direção ou coordenação da escola, para que o professor de Psicologia que atua nessa instituição atenda casos de alunos com dificuldades na aprendizagem, dificuldades nas relações interpessoais ou que encaminhe estes para acompanhamento psicológico especializado, atribuições estas do psicólogo escolar, e não do professor de Psicologia (Souza, 2007). Portanto, nota-se que é muito provável que, dentro da escola, os papéis de psicólogo escolar e professor de Psicologia ainda não tenham uma identidade clara por parte dos gestores e, por vezes, dos próprios profissionais da educação e Psicologia.

Frente a essa dificuldade de diferenciação quanto às atribuições, Souza (2007) aponta que a Psicologia Escolar, como campo de atuação, constituiu-se historicamente como uma área de aplicação da Psicologia, voltando-se para questões relacionadas aos problemas de aprendizagem, aconselhamento psicológico e vocacional, modificação de comportamentos em sala de aula e treinamento de professores. Portanto, para que o psicólogo escolar possa agir na perspectiva de intervenção dos processos que se dão no dia a dia da escola, precisará, antes de tudo, estabelecer uma relação que o permita intervir na dinâmica institucional da escola (Sekkel \& Machado, 2007).

Já no tocante ao ensino de Psicologia na escola, Souza (2007, p. 262) adverte que "este é um espaço eminentemente de formação, de socialização do conhecimento acumulado no campo da Psicologia, de reflexão sobre a constituição da subjetividade humana". Nesse sentido, ao ensino de Psicologia cabe a tarefa de formar os sujeitos escolares através da socialização das teorias psicológicas que tomam como referencial teórico temas do cotidiano dos alunos. Porém não basta simplesmente levar a cabo essas informações aos alunos, a grande atribuição da disciplina Psicologia na escola é a desnaturalização do estabelecido, tendo em vista sua dimensão histórico-social, analisando, junto aos alunos, as relações de poder, como se constituem as instituições como a escola e as relações sociais que nela se estabelecem (Souza, 2007). 
Outros autores (Machado \& Sekkel, 2013; Maciel, 2009) apontam para confusões que partem de alguns profissionais em exercício na docência em Psicologia no Ensino Médio que confundem sua atuação com a de um orientador profissional ou psicólogo clínico. É nesse aspecto que Maciel (2009, p. 20) analisa que ao licenciado em Psicologia cabe saber sobre sua identidade docente, ou seja, para que o licenciado atue efetivamente como professor de Psicologia na educação básica deverá "reconhecer-se como aquele que ensina conteúdos de Psicologia" e, dessa forma, atuar como professor de Psicologia, e não como psicólogo clínico na escola. Portanto, o psicólogo deve experimentar-se no campo da docência de modo a "ensaiar alternativas, agregar compromissos, rever seu aparato conceitual, contextualizar seu fazer, adquirir relevância", questionando-se sobre qual o significado da docência que pratica e se ela está comprometida e compreendida como prática social, transmissão de conhecimentos da psicologia, transposição da clínica psicológica, auxílio ao autoconhecimento ou problematização de saberes e fazeres (Pires, 2009, p. 116).

Fica claro, portanto, que o papel do ensino da disciplina de Psicologia na escola é de caráter educativo, social, formador e fomentador que traz, no cerne de suas intenções e discussões, a problematização de questões que são objeto de estudo da Psicologia como ciência. À Psicologia Escolar cabe a tarefa de intervenção psicológica propriamente dita. A importância de se afirmar essas diferenças se dá com propósito de enfatizar a função do professor como aquele que mediará a aprendizagem de conteúdos de cunho conceitual considerados importantes para a formação dos sujeitos, fazendo parte da equipe docente de uma escola (Sekkel \& Machado, 2007; Machado \& Sekkel, 2013).

Assim, é importante que a própria formação de professores de Psicologia, que ocorrerá eminentemente nas Instituições de Ensino Superior (IES), se dê no sentido de atenuar essas diferenças já no próprio curso de formação, diferenciando os papéis e atribuições, de um lado, do professor de Psicologia e, de outro, de psicólogo escolar. Por isso, é importante que, desde o início do curso de graduação em Psicologia, se façam presentes no discurso dos professores as possibilidades de atuação do futuro profissional, enfatizando que, dentre tantas possíveis e diversas áreas as quais o psicólogo poderá transitar, também está a docência em Psicologia.

\section{Reflexões sobre a Psicologia no Ensino Médio: perspectivas e desafios}

Ainda que o ensino de Psicologia se faça presente como objeto de pesquisas e estudos há cerca de três décadas, segundo Larocca (2007), essa preocupação com a nossa realidade educacional se deu, sobretudo, a partir dos anos 80, através da problematização da formação que efetivamente era praticada pelos professores nos cursos de licenciatura. É importante destacar que esses estudos e pesquisas estavam muito mais direcionados ao papel do ensino de Psicologia na formação de professores de nível superior do que com o papel do ensino desta disciplina na educação de nível médio.

Com relação à formação de professores, Pacheco e cols. (2011) percebem que a Psicologia pode oferecer um suporte teórico importante a esses profissionais, ampliando a compreensão, por parte do professor, de sua práxis em sala de aula, e fazendo com que este assuma que a escola é o lugar do convívio onde, inevitavelmente, se refletem situações da vida social, política, econômica e cultural. É nesse sentido que o ensino de Psicologia na educação básica visa a uma contribuição teórica e empírica de grande relevância e importância para os jovens, na medida em que as teorias psicológicas se aproximam e, de alguma forma, aludem ao cotidiano destes.

Ainda que a obrigatoriedade dos cursos de graduação em Psicologia em ofertar a formação complementar de professor de Psicologia seja recente, com a Resolução $n^{\circ}$ 5/2011, que "institui as Diretrizes Curriculares Nacionais para formação de professores de Psicologia" (CNE/MEC, 2011, p. 1), a formação de professores ou licenciatura em Psicologia é uma habilitação possível na formação do psicólogo desde a regulamentação da psicologia como profissão no país, implantada pela Lei $n^{\circ} 4.119 / 1962$, de 27/08/1962 (Cirino \& cols., 2007). Em seu artigo $1^{\circ}$, a lei que regulamenta a profissão de psicólogo disserta que "a formação em Psicologia far-se-á nas Faculdades de Filosofia, em cursos de bacharelado, licenciado e Psicólogo." (Lei n. 4.119, 1962, p. 1).

Segundo Cirino e cols. (2007), o que não fica claro na regulamentação de 1962 em relação à atuação do bacharel e do licenciado em Psicologia refere-se às atribuições destes dois segmentos, visto que a lei, em seu capítulo III, que disserta sobre os direitos conferidos aos diplomados, acaba por confundi-los. Ao analisar a lei supracitada, observa-se que, no artigo 11, há a prerrogativa de que "ao portador do diploma de Bacharel em Psicologia, é conferido o direito de Ensinar Psicologia em cursos de grau médio, nos termos da legislação em vigor" (Brasil, 1962, p. 2). Nessa mesma perspectiva, o artigo 12 continua enfatizando que ao portador de diploma de licenciado é conferido o direito de lecionar Psicologia.

Ainda fazendo-se uma análise da regulamentação de 1962, à luz do que propõe Cirino e cols. (2007), observa-se mais uma inconsistência, pois o artigo 13 do capítulo III continua "ao portador do diploma de psicólogo é conferido o direito de ensinar Psicologia nos vários cursos de que trata a lei, observadas as exigências legais específicas, e a exercer a profissão de psicólogo" (Brasil, 1962, p. 2), fazendo-se menção de que o diplomado, além de poder exercer a profissão de psicólogo, tem o direito de ensinar Psicologia, não especificando, no entanto, o local de atuação do profissional, assim como não o faz nos artigos 11 e 12. Como se pode observar, a primeira legislação que regulamenta a profissão no país carecia de clareza e pontualidade sobre quais as reais atribuições de cada modalidade no que concerne ao exercício profissional. Em suma, havia a prerrogativa, na Lei $n^{\circ} 4.119 / 1962$, de que a docência era uma atividade que 
contemplava as três modalidades de formação (bacharel, licenciado e psicólogo) e, nesta perspectiva, concebia-se o professor de Psicologia como um profissional no exercício da Psicologia (Cirino \& Miranda, 2013).

Segundo Barros (2007), a legislação de 1962 institui o estabelecimento de diretrizes que embasavam a formação do psicólogo concentrada em três grandes áreas: clínica, educacional e empresarial. Nesse sentido, a Psicologia aplicada se constituía como a base da formação de psicólogos no país e que tem repercussões nos cursos de formação de psicólogos até hoje, ainda que a licenciatura também figurasse como possiblidade de formação do profissional psicólogo. A hipótese sugerida pelo autor é de que a história da Psicologia no país transformou os psicólogos em profissionais que pensam essa ciência apenas em termos de sua aplicabilidade, o que acabou afastando-os da formação em licenciatura.

Por essa razão, o ensino de Psicologia no Ensino Médio vem sendo marcado por constâncias e inconstâncias, visto que a disciplina de Psicologia, em alguns momentos, aparece com maior importância e já, em outros, figura com menor frequência e importância no cenário educacional (Soligo \& Azzi, 2008). Porém, ainda com as oscilações que configuram a identidade do ensino de Psicologia no país, é relevante destacar que a mesma tem se feito presente tanto no Ensino Médio propedêutico quanto no técnico-profissionalizante. É considerada de extrema importância e relevância para áreas como saúde, administração, formação de professores, direito e relações humanas (Amado, 2013; Pandita-Pereira \& Sekkel, 2012; Soligo \& Azzi, 2008).

No que tange à presença da Psicologia no ensino de nível médio técnico e da habilitação do licenciado em Psicologia para fazer parte do corpo docente, observa-se que este está habilitado e faz parte do corpo docente de cursos de Ensino Médio técnico-profissionalizante como Administração, Recursos Humanos, entre outros (Amado, 2013; Soligo \& Azzi, 2008). Amado (2013, p. 80) alerta também que "na sua maioria, esses cursos técnicos, trazem em suas ementas, conteúdos relativos à Psicologia, tais como motivação humana, gestão de pessoas, afetividade, ética, questões da Psicologia relacionadas ao mundo do trabalho, saúde mental, dentre outros".

Essa instabilidade da presença da disciplina Psicologia no Ensino Médio regular se dá, segundo Barros (2007), no bojo de três questões fundamentais, que são: a primeira refere-se ao pouco interesse que profissionais psicólogos têm em relação à sua atuação como professores no Ensino Médio; a segunda concentra-se na reduzida oferta da opção de licenciaturas em cursos de Psicologia; e a terceira, e não menos importante, é relativa aos próprios professores de graduação em Psicologia que não acreditam que a disciplina de Psicologia, como formadora de um jovem cidadão/trabaIhador mais crítico no nível médio, seja passível de defesa e obrigatoriedade. Nesse sentido, Kohatsu (2010) menciona que a realidade do Ensino Médio e, consequentemente, as experiências de professores de Psicologia neste nível, são pouco conhecidas no meio acadêmico, o que pode desem- bocar em uma formação inicial comprometida de professores dessa disciplina.

A falta de debates com relação à formação de professores de Psicologia pode estar ligada à própria desvalorização da profissão docente no meio acadêmico, que, segundo Amado (2013, p. 80) é um fator que pode acabar "prejudicando a consideração que estudantes e docentes podem ter a respeito dessa modalidade da formação". Nesse interim, Pereira (1999) elenca uma série de fatores externos ao processo pedagógico que influem negativamente no processo de formação inicial e continuada de professores, a saber: a precariedade do trabalho escolar; o aviltamento salarial; as más condições de trabalho; as excessivas jornadas de trabalho; e a inexistência de um plano de carreira para a categoria, entre outros. Simões e Paiva (2007) também alertam que não se pode deixar de refletir também que os baixos investimentos na área da educação, mais precisamente na docência, a falta de concursos públicos, os baixos salários dos professores e, sobretudo, a falta de preparo específico do aluno repercutem para a falta de interesse pela carreira docente no Ensino Médio, a qual aumenta entre alunos de Psicologia.

Ainda a respeito da relevância dada ao ensino de Psicologia nas escolas, percebe-se que são escassas as pesquisas que se dedicam a estudar os cursos de licenciatura em Psicologia e mais raros ainda os que se debruçam sobre a problemática desse ensino no nível médio, ficando os estudos mais concentrados na investigação das contribuições da disciplina Psicologia da Educação na formação de professores oriundos de cursos de licenciatura (Kohatsu, 2010). Todavia, uma ação com o objetivo de valorizar o tema da formação de professores de Psicologia poderia ocorrer no sentido de se conhecer este profissional, pensar em quais são as finalidades que regem sua formação e também quais as possibilidades de campos de atuação do licenciado (Amado, 2013).

Apesar disso, é importante salientar que vem sendo empreendido esforço para delimitar aspectos conceituais que incidem diretamente na prática do licenciado em Psicologia. A delimitação da prática do psicólogo escolar e do professor de Psicologia no Ensino Médio vem sendo abordada nos estudos que tratam da temática (Machado \& Sekkel, 2013; Sekkel \& Machado, 2007; Souza, 2007, 2010). No que tange à diferenciação, os estudos são unânimes em apresentar a Psicologia Escolar como campo de atuação e aplicação da ciência psicológica no contexto educacional. Enquanto que à Psicologia no Ensino Médio cabe a formação dos sujeitos, recorrendo, para isso, à socialização dos conhecimentos acumulados pela ciência psicológica (Souza, 2007).

Porém, ainda que o cenário atual de pesquisas e estudos sobre o ensino de Psicologia se mostre incipiente, observa-se crescente mobilização da categoria no sentido de reavivar os estudos sobre o tema. Existem evidências documentais e publicações científicas que narram a trajetória, prolixa, de estudantes, professores e pesquisadores que vêm se dedicando a dar maior visibilidade à licenciatura em Psicologia, campo este já consolidado por lei no país. Um exemplo mais recente de como o ensino de Psicologia 
no Ensino Médio vem recebendo destaque é o Projeto de Lei $n^{\circ} 105$ (2007), de autoria da deputada Luiza Erundina, que prevê alteração nos dispositivos do artigo 36 da LDB (Lei $\left.n^{\circ} 9.394,1996\right)$. Esse projeto de lei, que ainda tramita no Congresso Nacional, propõe a inclusão da Psicologia, em conjunto com a Filosofia e a Sociologia, como disciplina obrigatória para o Ensino Médio.

\section{Considerações Finais}

Tendo em vista o exposto, observa-se um movimento histórico/atual pela retomada não só da disciplina Psicologia no Ensino Médio, mas, também, pela ampliação de discussões mais profundas no que concerne às implicações dessa disciplina para a formação dos sujeitos jovens.

Porém, constata-se, através dos materiais consultados para a presente revisão, que faltam dados empíricos a respeito da Psicologia no Ensino Médio. A hipótese para essa carência de dados e estudos que versem sobre o ensino de Psicologia no Ensino Médio reside no fato dos cursos de graduação em Psicologia priorizarem em seus currículos uma formação voltada para prática clínica.

No que se refere a quais conhecimentos e a que postura profissional esperar do psicólogo como partícipe do âmbito escolar, ficarão a cargo do docente/psicólogo os limites postos entre os ensinamentos psicológicos pertinentes à faixa etária e ao objetivo do curso trabalhado e quais temas se mostram pertinentes para estudo. Nesse sentido também ao psicólogo escolar caberá a prática psicológica dentro do contexto escolar.

Além disso, o presente artigo oportunizou uma aproximação teórica com relação às diferenças de atuação do psicólogo escolar e do professor de Psicologia na escola. Também foi possível realizar uma incursão na história do ensino de Psicologia no Ensino Médio brasileiro.

Assim, espera-se que o artigo ora apresentado se constitua como "mola propulsora" para futuros questionamentos e estudos que viabilizem uma relação mais estreita entre Psicologia e educação, colocando em evidência o papel social do professor de Psicologia como socializador dos conhecimentos psicológicos na educação básica.

\section{Referências}

Almeida, I.M.M.Z.P., Oliveira, R.R., Prazeres, S.M.G., Polônia A.C., Silva, A.A., Brandão, S.A., Pato, A., \& Cerqueira, T.C.S. (2007). Pedagogia: interfaces entre a psicologia e a educação. Brasília: Universidade de Brasília.

Amado, A.C.S. (2013). O Ensino de Psicologia: O Cenário Atual. Em M.C. Sekkel \& C.C. Barros (Orgs.), Licenciatura em psicologia: temas atuais (pp. 77-94). São Paulo: Zagodoni.

Barros, C.C. (2007). Reflexões sobre a formação de professores de Psicologia. Temas em Psicologia, 15 (1), 33-39.
Cirino, S.D., Knupp, D.F.D., Lemos, L.S., \& Domingues, S. (2007). As novas diretrizes curriculares: uma reflexão sobre a licenciatura em Psicologia. Temas em Psicologia, 15 (1), 23-32.

Cirino, S.D. \& Miranda, R.L. (2013). Ensinando Psicologia: Elementos para uma história sobre o Professor de Psicologia e a Licenciatura. Em M.C. Sekkel \& C.C. Barros (Orgs.), Licenciatura em psicologia: temas atuais (pp. 43-60). São Paulo: Zagodoni.

Conselho Nacional de Educação. Ministério da Educação [CNE/MEC] (2011). Resolução n. 5 de 15 março de 2011. Diretrizes curriculares nacionais para a os cursos de graduação em psicologia. Brasília: MEC.

Dadico, L. (2009). Práticas educacionais distintas: A psicologia no ensino médio paulista. Cadernos de Pesquisa, 39 (137), 421-440.

Dessen, M.A. \& Polonia, A.C. (2007). A Família e a Escola como Contextos de Desenvolvimento Humano. Paideia, 17(36), 21-32.

Gomes, A.M.M. (2012). O psicólogo na rede pública de Educação: possibilidade e desafios de uma atuação na perspectiva clínica. Dissertação de mestrado, Universidade de São Paulo, São PauloSP.

Klinko, J. \& Sekkel, M.C. (2010). Psicologia no ensino médio: sobre os desafios de ser professor. Psicologia: ensino \& formação, 1 (2), 73-83.

Kohatsu, L.N. (2010). A reinserção da disciplina de psicologia no ensino médio: as especificidades da psicologia e os desafios do atual contexto educacional. Psicologia: ensino \& formação, 1 (1), 53-66.

Larocca, P. (2007). Ensino de Psicologia e seus fins para formação de professores: uma discussão mais que necessária. Temas em Psicologia, 15 (1), 57-68.

Lei n. 4.119, de 27 agosto de 1962 (1962). Dispõe sobre os cursos de formação em Psicologia e regulamenta a profissão de Psicólogo. Brasília: MEC.

Lei n. 5.692, de 11 agosto de 1971 (1971). Lei de Diretrizes e Bases da Educação Nacional. Brasília: MEC.

Lei n. 7.044, de 18 outubro de 1982 (1982). Altera dispositivos da Lei n. 5.692. Brasília: MEC.

Lei n. 9.394, de 20 dezembro de 1996 (1996). Lei de Diretrizes e Bases da Educação Nacional. Brasília: MEC

Leite, S.A.S. (2007). Psicologia no Ensino Médio: desafios e perspectivas. Temas em Psicologia, 15 (1), 11-21.

Machado, A.M. \& Sekkel, M.C. (2013). Licenciatura em Psicologia: A Experiência do IPUSP. Em M.C. Sekkel \& C.C. Barros (Orgs.), Licenciatura em psicologia: temas atuais (pp. 147-160). São Paulo, Zagodoni. 
Maciel, M.S. (2009). Cursos técnicos: um campo de atuação para o licenciado em psicologia na cidade de Belo Horizonte. Dissertação de mestrado, Universidade Federal de Minas Gerais, Belo Horizonte-BH.

Massimi, M. (1993). Projetos de lei prevendo a inserção da Psicologia nos currículos do ensino superior e secundário no Brasil do século XIX. Psicologia: Teoria e Pesquisa, 9 (2), 261-269.

Mrech, L.M. (2007). Um breve histórico a respeito do ensino de psicologia. Educação Temática Digital, 8 (2), 255-235.

Mrech, L.M. (2013). O Ensino de Psicologia: A Imagem Escura de uma Profissão Difusa. Em M.C. Sekkel \& C.C. Barros (Orgs.), Licenciatura em psicologia: temas atuais (pp. 61-76). São Paulo, Zagodoni.

Molon, S.I. (2002). Entrelaçando a psicologia e a educação: uma reflexão sobre a formação continuada de educadores à luz da psicologia sócio-histórica. Contrapontos, 2 (5), 237-250.

Pacheco, A.P.L., Silva, E.D., Bogo, F.H.M., Agnes, L.A., \& Jesus, V.C. (2011). Docência em Psicologia: uma experiência no estágio de licenciatura em Psicologia. Psicologia Escolar e Educacional, 15 (2), 363-366.

Pandita-Pereira, A. \& Sekkel, M.C. (2012). Possibilidade de Atuação para o Licenciado em Psicologia nas Etecs. Psicologia: Ciência \& Profissão, 32 (4), 972-985.

Penteado, T.C.Z., \& Guzzo, R.S.L. (2010). Educação e psicologia: a construção de um projeto político-pedagógico emancipador. Psicologia \& Sociedade, 22 (3), 569-577.

Pereira, J.E.D. (1999). As licenciaturas e as novas políticas educacionais para a formação docente. Educação \& Sociedade, 20 (68), 109-125.

Perrenoud, P. (2013). Desenvolver Competências ou Ensinar Saberes: A Escola que Prepara para a Vida. Porto Alegre: Penso.
Pires, F.H. (2009). O Ensino de Psicologia na Educação Profissional: (des) compromissos docentes com a saúde. Dissertação de Mestrado, Universidade Federal do Rio Grande do Sul, Porto Alegre - RS.

Sekkel, M.C. \& Machado, A.M. (2007). O Projeto Pedagógico do curso de formação de professores de Psicologia do Instituto de Psicologia da USP. Temas em Psicologia, 15 (1), 127-134.

Silva, R.G.D. (2005). As Políticas Educacionais e a Psicologia no Ensino Médio: Uma Análise da Implantação da Disciplina de Psicologia numa Escola Pública no Estado do Paraná (19992002). Tese de doutorado, Universidade de Campinas, São PauloSP.

Silva, R.G.D. (2011). Relato de uma pesquisa sobre as contribuições da psicologia para o ensino médio. Psicologia: ensino \& formação, $2(1), 57-76$.

Simões, S.P. \& Paiva, M.G.V. (2007). Licenciatura em Psicologia: legislação e nova proposta curricular na Universidade do Estado do Rio de Janeiro. Temas em Psicologia, 15 (1), 115-125.

Soligo, A.F. \& Azzi, R.G. (2008). Psicologia no ensino médio. Disponível em: http://site.cfp.org.br/wp-content/uploads/2008/08/ ano-educacao.pdf. Acesso em: 21/09/2014.

Soligo, A.F., \& Azzi, R.G. (2009). Psicologia no ensino médio: desafios e perspectivas. Recuperado: 21 set. 2014. Disponível: http://www. abrapee.psc.br/documentos/Texto_Base_Eixo_4_Ensino_Medio. pdf.

Souza, M.P.R. (2007). A Psicologia escolar e o ensino de Psicologia: dilemas e perspectivas. Educação Temática Digital, 8 (2), 258-265.

Tiba, I. (2007). Juventude e drogas: anjos caídos. São Paulo: Integrare Editora.

Vechia, A. \& Lorenz, K.M. (1998). Programa de Ensino da Escola Secundária Brasileira: 1850-1951. Curitiba: Editora do Autor.

Recebido em: 25/11/2014

Reformulado em: 20/08/2015

Aprovado em: 14/09/2015

\section{Sobre o autor}

Lucas Antunes Machado (lucas.antunes@acad.pucrs.br)

Graduando em Psicologia pela Pontifícia Universidade Católica do Rio Grande do Sul. Bolsista de Iniciação Científica (PIBIC/FAPERGS) no Núcleo de Estudos e Pesquisa em Violência vinculado à Faculdade de Serviço Social e ao Programa de Pós-Graduação em Serviço Social (NEPEVI/FSS/PUCRS).

Este estudo não conta com financiamento da FAPERGS, porém agradeço a esta agência pela bolsa de IC que vem subsidiando minha formação como pesquisador. 